\title{
Clinical and Surgical Outcomes of Femtosecond Laser-Assisted Cataract Surgery (FLACS) on Hard Cataracts in the Egyptian Population
}

This article was published in the following Dove Press journal: Clinical Ophthalmology

\author{
Mohamed Gamal Ebidalla \\ Elghobaier (iD) \\ Mohamed Farag Khalil \\ Ibrahiem iD ${ }^{2}$ \\ Ahmed Shawkat Abdelhalim ${ }^{2}$ \\ Ahmed Mostafa Eid (iD ${ }^{2}$ \\ Khalid Al Said Murad ${ }^{2}$ \\ 'Oyoun Masr Center for LASIK \& Eye \\ Surgeries, Sohag, Egypt; ${ }^{2}$ Ophthalmology \\ Department, Minia Faculty of Medicine, \\ Minia University, Minia, Egypt
}

Objective: To evaluate the clinical and surgical outcomes of femtosecond laser-assisted cataract surgery (FLACS) in hard cataract of Egyptian population.

Setting: ICare Center, Alexandria, Egypt.

Design: Retrospective observational.

Methods: The study included 50 FLACS cases of 40 patients who had cataract; NO4 NC4 or more according to Lens Opacities Classification System III (LOCS III), performed between October 2018 and May 2019. The cases underwent anterior capsulotomy, lens fragmentation, and corneal incisions with the femtosecond laser. Arcuate keratotomy was performed in selected cases. Phacoemulsification and implantation of an intraocular lens are then performed.

Results: Patients mean age was $63.06 \pm 7.75 \mathrm{yr}$, mean femtosecond laser energy was $12.92 \pm$ $0.72 \mathrm{~mJ}$, mean docking time was $3.00 \pm 0.83 \mathrm{~min}$ and overall mean laser treatment time was $92.00 \pm 25.01 \mathrm{sec}$. Mean laser treatment time was lower in cases that did not get astigmatic keratectomy $(87.7 \pm 18.97$ vs $89.47 \pm 13.43 \mathrm{sec} ; \mathrm{p}<0.73)$. Attempted refraction was $-0.09 \pm$ $0.52 \mathrm{D}$ and achieved 12 months postoperative manifest sphere equivalent refraction (SER) was $-0.19 \pm 1.11 \mathrm{D}(\mathrm{r}=0.8$ and $\mathrm{P}<0.001)$. Mean error $(\mathrm{ME})$ was $-0.2 \pm 1.11$ (range: $-2.5-1.5$ ) while mean absolute error (MAE) was $0.97 \pm 0.57$ (range: $0-2.5$ ). Eighty percent and $92 \%$ of cases had 1 month postoperative SER within $1.0 \mathrm{D}$ and $1.5 \mathrm{D}$, respectively. One eye $(2 \%)$ had incomplete capsulotomy, 7 eyes (14\%) had incomplete corneal incision and lens fragmentation was complete in all cases except 1 eye (2\%). Thirty-four eyes (68\%) showed postdocking conjunctival ecchymosis and 35 eyes $(70 \%)$ had intraoperative miosis.

Conclusion: FLACS has low complication rate with effective results. High cost of technology is still the main barrier against its popularity.

Keywords: FLACS, astigmatic keratotomy, Egyptian, hard cataract

\section{Introduction}

Cataract surgery is the highest performed surgical procedure in the world. ${ }^{1}$ The World Health Organization estimates the number of cataract surgeries to be 32 million by the year $2020 .^{2}$

Femtosecond laser was introduced to the ophthalmic practice initially to create flaps in laser in situ keratomileusis (LASIK) and then was used in cataract surgery. ${ }^{3}$ The femtosecond laser is commercially available to perform key steps in cataract surgery: capsulotomy, lens fragmentation and wound construction as well as arcuate corneal incisions for astigmatic correction.
Correspondence: Mohamed Gamal Ebidalla Elghobaier

Tel +201226847046

Email elghobaier@gmail.com 
Although phacoemulsification is the most widely used procedure for cataract surgery, it still has some complications and concerns in challenging cases, eg, hard nuclei and weak zonules, which gave a potential advantage to the newer technology; FLACS as it decreases the need to high ultrasonic power thus decreasing the risk of endothelial cell damage and decreases intraoperative manual manipulation. ${ }^{4}$

Despite the clear benefits of FLACS, it is still not widespread yet because of the high cost of adoption of this technology. When the surgeons are professional and confident about their outcomes of the conventional phacoemulsification, it is hard to ask them to try a new technology with its own drawbacks. ${ }^{5,6}$

However, introduction of a new procedure to the clinical practice is associated with a learning curve. In this paper, we studied the clinical and surgical outcomes of FLACS according to our early experience with the procedure, dealing with hard cataract in Egyptian population.

\section{Patients and Methods}

This is a retrospective study that included 50 consecutive FLACS cases of 40 patients. Cases were performed at iCare Surgical Center, Alexandria, Egypt. All cases have been performed between October 2018 and May 2019.

The study conformed to the tenets of the Declaration of Helsinki. Ethical approval was obtained from Minia University human research ethics committee for the evaluation of the safety and success of the LenSx laser system (Alcon, Fort Worth, TX). Written informed consent was obtained before surgery from all patients, that included also review of their medical records, filming and photographic recording for research purposes.

Eligible candidates were examined before surgery to establish a baseline for their ocular condition. All cases had cataract of grade NO4 NC4or more according to Lens Opacities Classification System III (LOCS III), with otherwise normal ocular examination. Exclusion criteria were glaucoma, pseudoexfoliation, small pupils, corneal opacity, retinal pathology, narrow interpalpebral fissures and uncooperative or overly anxious patients.

\section{Procedure}

Patients underwent detailed preoperative clinical assessment that included slit-lamp biomicroscopy, tonometry, measurement of uncorrected and best-corrected distance visual acuity and manifest refraction. Investigations included measurement of axial length and biometry (IOLMaster Carl Zeiss Meditech, Inc., Dublin, CA), pachymetry and corneal topography (Allegro Oculyzer; Wavelight Fort Worth, TX), specular microscopy (Tomey, Nagoya, Japan).

Routine preoperative papillary dilation using $1 \%$ tropicamide and $10 \%$ phenylephrine followed by topical anesthesia using benoxinate hydrochloride $0.4 \%$ was done for all patients.

The LenSx system was programmed to perform capsulotomy, lens fragmentation pattern, primary and secondary incisions. Arcuate keratotomy was performed in selected cases of astigmatism (range: $0.75-1.50 \mathrm{D}$ ). This is followed by docking the patient's eye using a sterile disposable patient interface which is composed of a suction ring, an applanation lens and tubing system. The process is monitored using video microscope and when the cornea is properly applanated, suction was applied by the surgeon.

The system screen displays both live microscopic and optical coherence tomography (OCT) images of the anterior segment of the eye.

The patient is then moved to the operating room (OR) to complete the surgery under complete sterile conditions as a standard phacoemulsification procedure using Infiniti unit (Alcon, Inc., Fort Worth, TX).

Postoperative regimen included $0.5 \%$ moxifloxacin (Vigamox; Alcon Inc., Alcon Labs Inc, Fort Worth, TX) 4 times a day for 2 weeks, $0.1 \%$ dexamethasone and $0.3 \%$ tobramycin combination (Tobradex; Alcon Inc., Alcon Labs Inc, Fort Worth, TX) 4 times a day for 2 weeks then tapered to twice a day for another 2 weeks.

Postoperative follow-up visits were at 1 day, 1 week, 1 month, 6 months and 12 months. The following data were measured preoperatively and during the postoperative followup period: Endothelial mean cell density (MCD), uncorrected and best-corrected distance visual acuity (UCDVA\& BCDVA) in $\operatorname{logMar}$ and both manifest sphere equivalent refraction (SER) and corneal astigmatism in diopters.

We have also measured the mean error (ME) which is the difference between postoperative manifest spherical equivalent and predicted postoperative target refraction and the mean absolute error (MAE) which is the average of the absolute values of the deviation from predicted postoperative refraction.

\section{Statistical Analysis}

This was carried out using SPSS for Windows Version 19 (IBM/SPSS Inc. Chicago, IL, USA) to analyze data and to get descriptive statistics. A P-value $<0.05$ was considered to be statistically significant. Pearson correlation coefficient was used to assess the correlation between different variables 
Table I Preoperative Data of the Patients Included in the Study

\begin{tabular}{|l|l|l|l|l|}
\hline & Minimum & Maximum & Mean & $\begin{array}{l}\text { Std. } \\
\text { Deviation }\end{array}$ \\
\hline Axial length & 19.33 & 32.76 & 23.4330 & 2.71572 \\
AC depth & 2.82 & 3.22 & 3.0414 & 0.10566 \\
PC IOL power & 3 & 29 & 19.22 & 5.933 \\
BCDVA & 0.5 & 1.0 & 0.746 & 0.146 \\
UCDVA & 0.1 & 1.0 & 0.808 & 0.164 \\
Manifest SE & -6.50 & 4.50 & -0.645 & 3.014 \\
CCT & 448 & 603 & 517.24 & 41.299 \\
MCD & 2003 & 2998 & 2558.82 & 344.953 \\
Keratometric & 0.25 & 5.00 & 2.0150 & 1.03314 \\
astigmatism & & & & \\
\hline
\end{tabular}

under normal conditions. Microsoft Office Excel 2016 (Microsoft Redmond, WA, USA) was used to get chart representation of preoperative and postoperative data during the follow-up period.

\section{Results}

A total of 50 eyes of 40 patients were included in the study. The mean age of the patients was $63.06 \pm 7.75$ years. Table 1 lists the preoperative data of patients included in the study while Table 2 illustrates changes of MCD, UCDVA, BCDVA, SER and corneal astigmatism all over the follow-up period.

Figure 1 shows chart representation of the changes in MCD preoperatively and during the follow-up period.

Mean femtosecond laser energy used was $12.92 \pm 0.72 \mathrm{~mJ}$ (range: $11.00-14.00 \mathrm{~mJ}$ ) while mean docking time was $3.00 \pm$ 0.83 minutes (range: $1.00-5.00$ minutes). We have also estimated the mean laser treatment time as $92.00 \pm 25.01$ seconds (range: 100-140 seconds).

Attempted refraction in this study was $-0.09 \pm 0.52$ and achieved 12-month postoperative manifest SER was $-0.19 \pm 1.11$ which shows a very highly significant strong correlation $(\mathrm{r}=0.8$ and $\mathrm{P}<0.001)$.
Mean error (ME) for this study was $-0.2 \pm 1.11$ (range: $-2.5-1.5$ ) while mean absolute error (MAE) was $0.97 \pm 0.57$ (range: $0-2.5$ ).

In cases that had astigmatic keratotomy, we have noticed that although the mean laser treatment time was longer among those patients with astigmatic keratotomy (89.47 \pm $13.43 \mathrm{sec})$ compared to those without $(87.7 \pm 18.97$ second $)$; the difference was non-significant $(\mathrm{p}<0.73)$. This may be explained by the limited number of cases and the relative wide SD compared to mean. Figure 2 shows chart representation of the changes in corneal astigmatism preoperatively and during the follow-up period.

Predictability of the postoperative manifest SER on the first postoperative month was reasonable as it showed that $80 \%$ and $92 \%$ of cases were within $1.0 \mathrm{D}$ and $1.5 \mathrm{D}$, respectively (Table 3).

Although we have reported no cases of programming errors, we had an interesting case of corneal grid pattern that resulted from sudden unexpected movement of the patient during lens fragmentation, which leads to application of laser to the cornea instead of the lens. That was the only case of failed lens fragmentation (2\%). Only one eye (2\%) had incomplete capsulotomy that necessitated completion using capsulurhexisforeceps. Seven eyes (14\%) had incomplete corneal incisions that were completed using a sharp keratome.

Thirty-four eyes (68\%) showed postdocking conjunctival ecchymosis which was considered as a minor complication that necessitates only good patient education. Although miosis (pupil constriction $\geq 2 \mathrm{~mm}$ comparing pupil size before and after FLACS treatment) was common in this study (70\%), it did not make any intraoperative troubles to the surgeon. We needed to use Malyugin ring to dilate the pupil in 1 case $(2 \%)$.

Figure 3 represents some of the abovementioned complications. Other intraoperative and postoperative complications related to phacoemulsification were not reported in this study.

Table 2 Patients' Data Preoperatively and Over 12 Month Postoperative Follow-Up Period

\begin{tabular}{|c|c|c|c|c|c|}
\hline Parameter & Preoperative & I m Postoperative & $6 \mathrm{~m}$ Postoperative & $12 \mathrm{~m}$ Postoperative & $\begin{array}{l}\text { P value (in the Postoperative } \\
\text { Period) }\end{array}$ \\
\hline MCD & 2559 & 2456 & 2463 & 2461 & 0.001 \\
\hline UCDVA & 0.81 & 0.15 & 0.17 & 0.14 & 0.02 \\
\hline BCDVA & 0.75 & 0.08 & 0.11 & 0.07 & 0.03 \\
\hline SER & -0.65 & -0.12 & -0.17 & -0.19 & 0.03 \\
\hline $\begin{array}{l}\text { Corneal } \\
\text { astigmatism }\end{array}$ & 1.09 & 0.39 & 0.61 & 0.63 & 0.04 \\
\hline
\end{tabular}




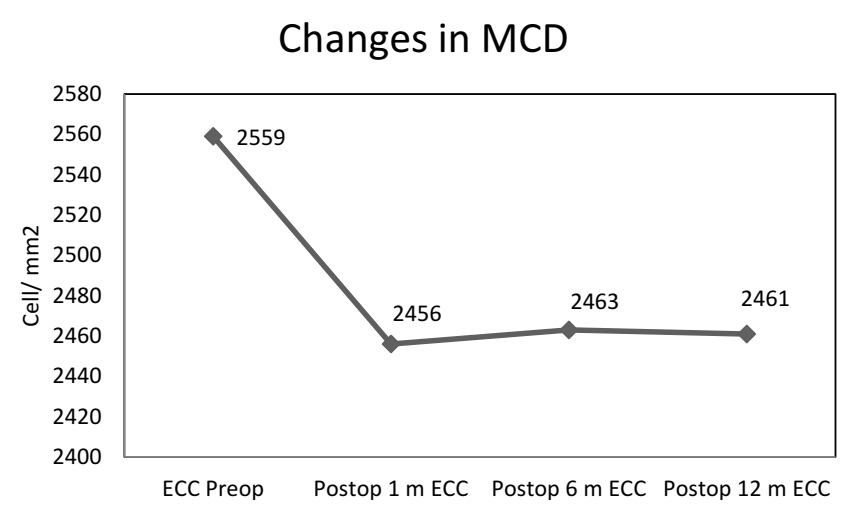

Figure I Changes in MCD preoperatively and during the follow-up period.

\section{Changes in keratometric astigmatism}

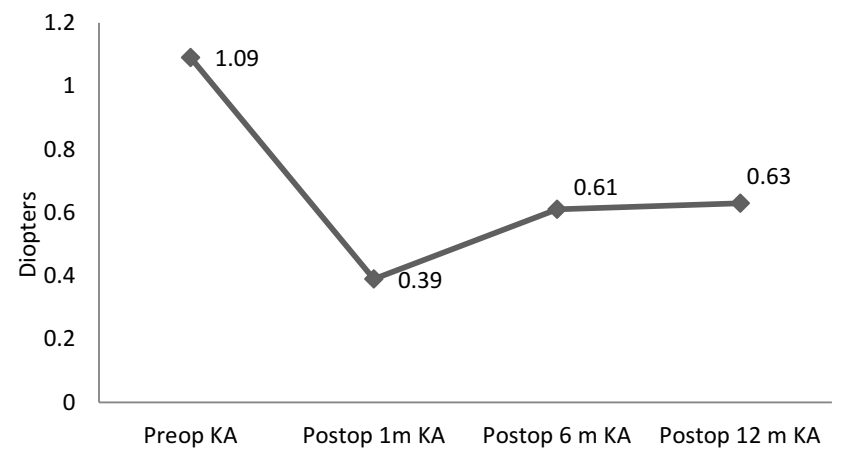

Figure 2 Changes in keratometric astigmatism preoperatively and during the follow-up period.

\section{Discussion}

Femtosecond lasers were initially developed for LASIK flap creation during corneal refractive surgery. Laser technology recently enabled surgeons to perform precise capsulotomy, lens fragmentation, and corneal incisions during cataract surgery. ${ }^{7}$

The aim of this study was to evaluate the efficacy and safety of FLACS. Cases were performed by a single experienced surgeon and this is important as it eliminates the effect of learning curve as demonstrated in the literature. ${ }^{8}$

Different studies tried to investigate the clinical outcomes of femtosecond laser-assisted cataract surgery as in a study of Bissen-Miyajima et $\mathrm{al}^{9}$ assessed the safety and efficacy of femtosecond laser-assisted cataract surgery (FLACS) in 529 eyes of 312 patients who underwent FLACS from 2013 to 2016 in a retrospective case series.

Preoperative UCDVA and BCDVA were $0.81 \pm 16$ and $0.75 \pm 0.17$, respectively, which improved up to $0.15 \pm 0.12$ and $0.08 \pm 1.11$, respectively, starting from the first
Table 3 Postoperative Range of Manifest SER and Refractive Predictability. The Highlighted Range of the Table Shows That $80 \%$ and $92 \%$ of Cases Had I Month Postoperative SER Within I.O D and I.5 D, Respectively

\begin{tabular}{|l|l|l|l|}
\hline Postop SER & Frequency & Percent & $\begin{array}{l}\text { Cumulative } \\
\text { Percent }\end{array}$ \\
\hline-0.5 to 0.5 & 24 & 48.0 & 48.0 \\
- I to I & 16 & 32.0 & 80.0 \\
-1.5 to 1.5 & 6 & 12.0 & 92.0 \\
Less than $-I .5$ or & 4 & 8.0 & 100.0 \\
higher than +1.5 & & 100.0 & \\
Total & 50 & & \\
\hline
\end{tabular}

postoperative day and this effect was quite stable during the follow-up period of 12 months.

These refractive results were supported by many studies that showed significant improvement in visual parameters post FLACS. A study by Lundström et $\mathrm{al}^{10}$ described a large cohort of cataract cases in 18 cataract surgery clinics in 9 European countries and Australia; they found that the visual outcomes of FLACS were favorable especially when compared with manual phacoemulsification.

In a study of Ranjini et al ${ }^{11}$ on 55 eyes of 55 patients who compared the outcomes of FLACS to standard $2.2 \mathrm{~mm}$ clear corneal phacoemulsification, they found that no significant difference was found between the groups for UCDVA at 4 weeks postoperatively while the FLACS group had better BCDVA ( $\mathrm{P}=0.0294)$.

As regards the manifest SER, the preoperative manifest SER was $-0.65 \pm 3.01$ which improved at the first postoperative month up to $-0.12 \pm 1.1$ and the effect of improvement was stable during the follow-up period with little fluctuations until reached $-0.2 \pm 1.11$ at the end of follow-up period of 12 months.

There is a very highly significant strong correlation between attempted refraction and achieved postoperative manifest SER $(\mathrm{r}=0.8$ and $\mathrm{P}<0.001)$.

Patients with corneal astigmatism were 19 patients who underwent astigmatic keratotomy. Our results showed that the mean preoperative corneal astigmatism was $1.1 \pm 0.23$ D improved to $0.4 \pm 1.1 \mathrm{D}$ at the 1 st postoperative month. Results showed mild regression with stable final result at the 12th month follow-up with a mean of $0.63 \pm 1.1 \mathrm{D}$.

The previous results coincide with Day et $\mathrm{al}^{12}$ who described the effect of femtosecond laser intrastromal astigmatic keratotomy performed during cataract surgery in a prospective case series study including 133 patients who showed that the mean astigmatism correction was $63 \%$. 


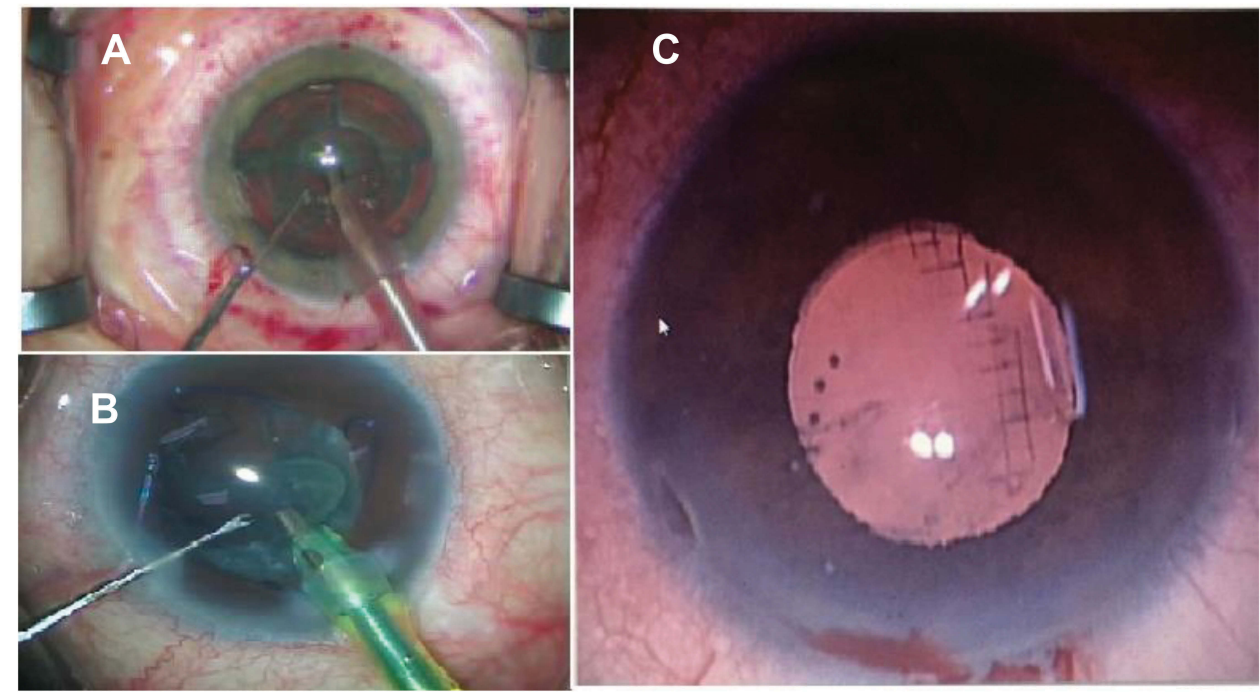

Figure 3 FLACS complications: (A) post docking conjunctival ecchymosis. (B) Intraoperative miosis managed with Malyugin ring. (C) Corneal laser grid pattern.

Chan et $\mathrm{al}^{13}$ investigated the stability of corneal astigmatism after combined FLACS and arcuate keratotomy in retrospective, interventional case series study. The mean preoperative corneal astigmatism was $1.35 \pm 0.48 \mathrm{D}$ which reduced to $0.67 \pm 0.54 \mathrm{D}$ at 2 months and $0.74 \pm 0.53 \mathrm{D}$ at 2 years postoperatively $(\mathrm{P}<0.001)$.

Injury reduction of corneal endothelial cells contributes to shortening the recovery period and improves visual outcomes. ${ }^{4,14,15}$ Based on the advantages of FLACS over phacoemulsification, some researchers have even predicted that the femtosecond laser will become the standard method of cataract extraction within 10 years. ${ }^{16}$

In our study, the mean preoperative MCD which was $2558.82 \pm 335$ decreased to $2455.78 \pm 335$ on month 1 postoperative follow-up by specular microscopy. Follow up after 6 and 12 months showed no statistically significant change during the follow-up period.

Many studies support our results ${ }^{5}$ while in a study of Abell and colleagues they found no difference in endothelial cell loss between the FLACS and standard cataract surgery 3 weeks post-operatively. ${ }^{17}$

FLACS has a lower complication rate compared with standard phacoemulsification, particularly in certain challenging situations. ${ }^{18-22}$ In this study, we have reported few technical and intraoperative complications which were not serious or vision-threatening. Although were not significant and did not affect the outcome of the surgery.

We have noticed that miosis and postdocking conjunctival ecchymosis were common in our study; $70 \%$ and $68 \%$, respectively. These findings were supported by previous studies such as Schultz et al who found that high levels of prostaglandins in the AC could be responsible for post-FLACS miosis. ${ }^{23}$ However, we cannot conclude that dark colored irides as in our community are associated with this high chance of intraoperative miosis. Ibrahim et al in their study of the correlation between the FLACS related miosis and iris color, on 137 patients divided into 3 groups according to the iris color, found that patients with light colored irides showed more significant miosis than patients with dark colored irides. ${ }^{24}$

Conjunctival ecchymosis showed wide variability in previous studies. Pajic et $\mathrm{al}^{25}$ reported no postoperative conjunctival bleeding at all while Palanker et $\mathrm{al}^{26}$ reported $80 \%$ conjunctival petechial hemorrhage and vasodilatation related to the suction ring. The high percentage of post docking conjunctival bleeding that we have found in our study could be related to the high incidence of trachoma causing increased limbal vascularization.

A rare complication that we have found is sudden suction loss which resulted in laser application to the cornea leading to a corneal grid pattern. This complication was described in a few published case reports. ${ }^{27-29}$

This study demonstrates that although femtosecond laser made the surgical steps of cataract surgery more predictable, it still has to be further studied in large multicenter studies to justify the benefits against the high cost of the technology, particularly many recent studies concluded that there was no statistically significant difference between FLACS and standard phacoemulsification in terms of visual outcomes and complications. ${ }^{30-32}$ 


\section{Data Sharing Statement}

The Excel Sheet data used to support the findings of this study are available from the corresponding author upon request.

\section{Acknowledgment}

The authors thank Prof. Dr. Ahmed E. Shama for performing surgery and allowing us to access the patient's data to conduct this study.

\section{Disclosure}

The article has not been presented in a meeting. The authors did not receive any financial support from any public or private sources. The authors have no financial or proprietary interest in a product, method, or material described herein and report no conflicts of interest.

\section{References}

1. Trikha S, Turnbull AM, Morris RJ, Anderson DF, Hossain P. The journey to femtosecond laser-assisted cataract surgery: new beginnings or false dawn? Eye. 2013;27(4):461-473. doi:10.1038/ eye. 2012.293

2. Brian G, Taylor H. Cataract blindness - challenges for the $21 \mathrm{st}$ century. Bull World Health Org. 2001;79:249-256.

3. Nagy Z, Takacs A, Filkorn T, Sarayba M. Initial clinical evaluation of an intraocular femtosecond laser in cataract surgery. J Refract Surg. 2009;25(12):1053-1060. doi:10.3928/1081597X-20091117-04

4. Conrad-Hengerer I, Al Juburi M, Schultz T, Hengerer FH, Dick HB. Corneal endothelial cell loss and corneal thickness in conventional compared with femtosecond laser-assisted cataract surgery: threemonth follow-up. J Cataract Refract Surg. 2013;39(9):1307-1313.

5. Uy HS, Edwards K, Curtis N. Femtosecond phacoemulsification: the business and the medicine. Curr Opin Ophthalmol. 2012;23 (1):33-39. doi:10.1097/ICU.0b013e32834cd622

6. Abell RG, Vote BJ. Cost-effectiveness of femtosecond laser-assisted cataract surgery versus phacoemulsification cataract surgery. Ophthalmology. 2014;121(1):10-16. doi: 10.1016/j.ophtha.2013. 07.056.

7. Ratkay-Traub I, Ferincz IE, Juhasz T, Kurtz RM, Krueger RR. First clinical results with the femtosecond neodymium-glass laser in refractive surgery. J Refract Surg. 2003;19(2):94-103.

8. Bali SJ, Hodge C, Lawless M, Roberts TV, Sutton G. Early experience with the femtosecond laser for cataract surgery. Ophthalmology. 2012;119(5):891-899. doi:10.1016/j.ophtha.2011.12.025

9. Bissen-Miyajima H, Hirasawa M, Nakamura K, Ota Y, Minami K. Safety and reliability of femtosecond laser-assisted cataract surgery for Japanese eyes. Jpn J Ophthalmol. 2018;62(2):226-230. doi: 10.1007/s10384-017-0553-6.

10. Lundström M, Dickman M, Henry Y, et al. Femtosecond laser-assisted cataract surgeries reported to the European registry of quality outcomes for cataract and refractive surgery: baseline characteristics, surgical procedure, and outcomes. J Cataract Refract Surg. 2017;43(12):1549-1556. doi:10.1016/j.jcrs.2017.09.029

11. Ranjini H, Murthy PR, Murthy GJ, Murthy VR. Femtosecond laser-assisted cataract surgery versus $2.2 \mathrm{~mm}$ clear corneal phacoemulsification. Indian J Ophthalmol. 2017;65(10):942-948. doi:10.4103/ijo.IJO_152_17
12. Day AC, Lau NM, Stevens JD. Non penetrating femtosecond laser intrastromal astigmatic keratotomy in eyes having cataract surgery. $J$ Cataract Refract Surg. 2016;42(1):102-109. doi:10.1016/j. jers.2015.07.045

13. Chan TC, Ng AL, Cheng GP, Wang Z, Woo VC, Jhanji V. Corneal astigmatism and aberrations after combined femtosecond-assisted phacoemulsification and arcuate keratotomy: two-year results. Am J Ophthalmol. 2016;170:83-90. doi:10.1016/j.ajo.2016.07.022

14. Al-Mohtaseb Z, He X, Yesilirmak N, Waren D, Donaldson KE. Comparison of corneal endothelial cell loss between two femtosecond laser platforms and standard phacoemulsification. J Refract Surg. 2017;33(10):708-712. doi: 10.3928/1081597X-20170731-01.

15. Krarup T, Ejstrup R, Mortensen A, la Cour M, Holm LM. Comparison of refractive predictability and endothelial cell loss in femtosecond laser-assisted cataract surgery and conventional phaco surgery: prospective randomised trial with 6 months of follow-up. BMJ Open Ophthalmol. 2019;4(1):e000233. doi: 10.1136/bmjophth2018-000233.

16. Ranka M, Donnenfeld ED. Femtosecond laser will be the standard method for cataract extraction ten years from now. Surv Ophthalmol. 2015;60(4):356-360. doi: 10.1016/j.survophthal.2015. 02.001 .

17. Abell RG, Kerr NM, Vote BJ. Toward zero effective phacoemulsification time using femtosecond laser pretreatment. Ophthalmology. 2013;120(5):942-948. doi:10.1016/j.ophtha.2012.11.045

18. Chen M, Swinney C, Chen M. Comparing the intraoperative complication rate of femtosecond laser-assisted cataract surgery to traditional phacoemulsification. Int J Ophthalmol. 2015;8(1):201-203. doi:10.3980/j.issn.2222-3959.2015.01.34

19. Cavallini GM, Fornasari E, De Maria M, Lazzerini A, Campi L, Verdina T. Bimanual femtosecond laser-assisted cataract surgery compared to standard bimanual phacoemulsification: a case-control study. Eur J Ophthalmol. 2019;29(6):629-635. doi:10.1177/ 1120672118805323

20. Yong WW, Chai HC, Shen L, Manotosh R, Tan WT. Comparing outcomes of phacoemulsification with femtosecond laser-assisted cataract surgery in patients with fuchs endothelial dystrophy. $\mathrm{Am}$ J Ophthalmol. 2018;196:173-180. doi: 10.1016/j.ajo.2018.08.006

21. Zhu Y, Chen X, Chen P, et al. Lens capsule-related complications of femtosecond laser-assisted capsulotomy versus manual capsulorhexis for white cataracts. J Cataract Refract Surg. 2019;45(3):337-342. doi: $10.1016 /$ j.jcrs.2018.10.037.

22. Conrad-Hengerer I, Hengerer FH, Joachim SC, Schultz T, Dick HB. Femtosecond laser-assisted cataract surgery in intumescent white cataracts. J Cataract Refract Surg. 2014;40(1):44-50. doi:10.1016/j. jers.2013.08.044

23. Schultz T, Joachim SC, Kuehn M, Dick HB. Changes in prostaglandin levels in patients undergoing femtosecond laser-assisted cataract surgery. J Refract Surg. 2013;29(11):742-747. doi: 10.3928/ 1081597X-20131021-03.

24. Ibrahim T, Goernert P, Rocha G. The role of iris color in femtosecond laser-induced miosis in patients undergoing cataract surgery. Ann Clin Ophthalmol. 2017;1(1):1001.

25. Pajic B, Vastardis I, Gatzioufas Z, Pajic-Eggspuehler B. First experience with the new high-frequency femtosecond laser system (LDV Z8) for cataract surgery. Clin Ophthalmol. 2014;8:2485. doi:10.2147/ OPTH.S72983

26. Palanker DV, Blumenkranz MS, Andersen D, et al. Femtosecond laser-assisted cataract surgery with integrated optical coherence tomography. Sci Transl Med. 2010;2(58):58ra85. doi: 10.1126/ scitranslmed.3001305.

27. Lubahn JG, Kankariya VP, Yoo SH. Grid pattern delivered to the cornea during femtosecond laser-assisted cataract surgery. J Cataract Refract Surg. 2014;40(3):496-497. doi: 10.1016/j.jcrs.2013.12.001. 
28. Chen CC, Sundar G. Inadvertent corneal laser application in femtosecond laser-assisted cataract surgery. JCRS Online Case Rep. 2016;4(3):45-48. doi: 10.1016/j.jcro.2016.04.001.

29. Schultz T, Dick HB. Suction loss during femtosecond laser-assisted cataract surgery. J Cataract Refract Surg. 2014;40(3):493-495. doi: 10.1016/j.jcrs.2013.12.004.

30. Manning S, Barry P, Henry Y, et al. Femtosecond laser-assisted cataract surgery versus standard phacoemulsification cataract surgery: study from the European Registry of Quality Outcomes for Cataract and Refractive Surgery. J Cataract Refract Surg. 2016;42 (12):1779-1790. doi: 10.1016/j.jcrs.2016.10.013.
31. Popovic M, Campos-Möller X, Schlenker MB, Ahmed II. Efficacy and safety of femtosecond laser-assisted cataract surgery compared with manual cataract surgery: a meta-analysis of 14567 eyes. Ophthalmology. 2016;123(10):2113-2126. doi: 10.1016/j. ophtha.2016.07.005.

32. Roberts HW, Day AC, O'Brart DP. Femtosecond laser-assisted cataract surgery: a review. Eur J Ophthalmol. 2020;30(3):417-429. doi: $10.1177 / 1120672119893291$

\section{Publish your work in this journal}

Clinical Ophthalmology is an international, peer-reviewed journal covering all subspecialties within ophthalmology. Key topics include: Optometry; Visual science; Pharmacology and drug therapy in eye diseases; Basic Sciences; Primary and Secondary eye care; Patient Safety and Quality of Care Improvements. This journal is indexed on PubMed

Submit your manuscript here: https://www.dovepress.com/clinical-ophthalmology-journal
Central and CAS, and is the official journal of The Society of Clinical Ophthalmology (SCO). The manuscript management system is completely online and includes a very quick and fair peer-review system, which is all easy to use. Visit http://www.dovepress.com/ testimonials.php to read real quotes from published authors. 